\title{
Short-term quality of life change perceived by patients after transition to mandibular overdentures
}

\section{Alessandra Julie SCHUSTER(a) Raissa Micaella \\ MARCELLO-MACHADO(b) \\ Amália Machado BIELEMANN(a) \\ Gustavo Giacomelli \\ NASCIMENTO(a) \\ Luciana de Rezende PINTO(c) \\ Altair Antoninha DEL BEL CURY(b) \\ Fernanda FAOT $^{(d)}$}

(a) Universidade Federal de Pelotas - UFPEL, Graduate Program in Dentistry, Pelotas, RS, Brazil.

(b) Universidade Estadual de

Campinas - Unicamp, Piracicaba Dental School, Department of Prosthodontics and Periodontology, Piracicaba, SP, Brazil.

(c) Universidade Federal de Pelotas - UFPEL, School of Dentistry, Department of Restorative Dentistry, Pelotas, RS, Brazil.

(d) Universidade Federal de Pelotas - UFPEL, School of Dentistry, Department of Restorative Dentistry, Pelotas, RS, Brazil.

Declaration of Interests: The authors certify that they have no commercial or associative interest that represents a conflict of interest in connection with the manuscript.

Corresponding Author:

Fernanda Faot

E-mail: fernanda.faot@gmail.com

Submitted: Jun 01, 2016

Accepted for publication: Nov 01, 2016

Last revision: Nov 21, 2016
Abstract: The aim of this longitudinal observational study was to evaluate the oral health-related quality of life (OHRQoL) following patient rehabilitation with implant-retained mandibular overdentures (IMO) and to identify the contribution of the different domains to OHRQoL. The Oral Health Impact Profile (OHIP-EDENT), Dental Impact on Daily Living (DIDL), and Geriatric Oral Health Assessment Index (GOHAI) questionnaires were completed twice by 25 patients: after 3 months of rehabilitation with complete dentures (CD) and after 3 months of IMO loading using stud abutments. The evaluation after IMO rehabilitation showed significant improvement in three DIDL domains: appearance $(p=0.011)$, eating and chewing $(p=0.003)$, and general performance $(p=0.003)$. The GOHAI results showed significant differences in two domains: psychosocial $(p=0.005)$ and pain and discomfort $(p=0.0004)$. The OHIP-EDENT outcomes showed significant improvements in five domains: functional limitation $(p=0.0001)$, physical pain $(p=0.0002)$, physical disability $(p=0.0010)$, and psychological disability and handicap $(p=0.032)$. The largest observed effect sizes were close to one standard deviation and were observed in the eating and chewing domain (0.93) of the DIDL; the pain and discomfort domain (0.83) of the GOHAI, and the functional limitation (0.89), physical pain (1.02), physical disability (0.84) domains of the OHIP-EDENT. The percentage of satisfied patients increased in all domains. Self-reported OHRQoL of CD wearers was significantly improved after 3 months of treatment with IMO, especially concerning the functional and pain-related aspects.

Keywords: Oral Health; Quality of Life; Denture, Overlay; Surveys and Questionnaires; Dental Implants.

\section{Introduction}

Edentulism is one of the most common conditions among oral health disorders and affects $2.3 \%$ of the world population, which represents 158 million people worldwide. ${ }^{1,2}$ According to current estimates, edentulism will continue to be one of the most common diseases in the elderly. ${ }^{3}$ Felton $^{4}$ stated that the necessity of complete denture (CD) therapy will probably not disappear over the next 4 to 5 decades. However, a substantial portion of $\mathrm{CD}$ wearers is not satisfied with rehabilitation. ${ }^{5}$ 
Alveolar ridge reabsorption occurs after dental extraction and modifies the oral cavity tissues due to alteration of stimuli in the jaw bone, thereby reducing the area supporting the prosthesis, which is much more severe in the mandible. ${ }^{6}$ This important consequence of edentulism is inevitable and progressive, and results in insufficient retention and stability of CD. ${ }^{5}$

Other problems associated with tooth loss and alveolar ridge reduction include a painful sensation in response to occlusal loads, food intolerance and mucosal reactivity, nutritional changes resulting from eating difficulties, speech difficulties, abnormal facial appearance, social relationship impacts, and even emotional problems. ${ }^{78}$ Studies report that the absence of mandibular denture retention and stability is the main reason for denture dissatisfaction and it has a direct impact on oral health-related quality of life (OHRQoL) ${ }^{5,9}$ Aesthetics and functional aspects of conventional dentures also affect social behavior and self-confidence. ${ }^{10}$

Locker et al. ${ }^{11}$ defined OHRQoL as "the extent to which oral disorders affect the functioning and psychosocial well-being. Currently, OHRQoL is considered an essential factor for assessment of the treatment success of implant-retained mandibular overdentures (IMO). ${ }^{12,13,14}$ However, patients with long-term edentulism have thin alveolar ridges, which hinders installation of conventional diameter implants. ${ }^{15}$ Therefore, narrow diameter dental implants (NDIs) are an effective alternative to rehabilitate edentulous mandibles with moderate to severe atrophy. ${ }^{15}$ NDI installation is a simple surgical technique and does not require bone grafting, so this minimally invasive procedure is associated with low morbidity and high survival rates. ${ }^{16,17,18}$ Longitudinal studies with follow-up periods of 6 years reported satisfactory NDI survival rates for mandibular overdentures, ranging from $94 \%$ to $98 \%{ }^{18}$

Since 1990, several measurement instruments for OHRQoL assessment have emerged, were validated, and are now widely used. Some of the most widely used tools specifically designed for edentulous patients are the GOHAI (Geriatric Oral Health Assessment Index), ${ }^{19}$ the DIDL (Dental Impact on Daily Living) ${ }^{20}$ the OHIP (The Oral Health Impact Profile), ${ }^{21}$ and abbreviated versions (the OHIP- $14^{22}$ and
OHIP-EDENT $\left.{ }^{23}\right)$. These questionnaires are answered by the patient and indicate the impact of oral health on quality of life through scores of physical, social, and psychological aspects.

So far, a number of studies have examined the subjective perception of denture wearers who were converted to IMO., ${ }^{9,24,25,26,27}$ However, the majority of these studies solely focused on the OHIP-EDENT questionnaire and the results were based on assessment of only one OHRQoL questionnaire.

The aim of the present study was to expand these previous works by evaluating the impact of IMO treatment with two implants on OHRQoL using three questionnaires (OHIP-EDENT, DIDL, and GOHAI), and by quantifying the relative improvement of each functional domain through effect size (ES) calculations. The latter allows the identification of which domain (physical, social, or psychological) achieved the highest improvement in response to treatment, as perceived by the patient.

\section{Methods}

\section{Experimental design}

In this longitudinal observational study, OHRQoL assessment was conducted before and after intervention. All procedures involving human participants were performed in accordance with the ethical standards of the institutional and national research committees, and the 1964 Helsinki declaration, as revised in 2008. The findings of this study were reported in accordance with the Strengthening the Reporting of Observational Studies in Epidemiology guidelines. The study protocol was approved by the local Research Ethics Committee (approval no. 69/2013) and included conventional dentures wearers receiving treatment at the Complete Denture Clinic of the School of Dentistry, Universidade Federal de Pelotas (Pelotas, RS, Brazil) from February 2013 to April 2014. Patients in good general health and wearing new conventional $\mathrm{CD}$ for at least 3 months, but experienced difficulties adapting to mandibular $\mathrm{CD}$, were invited to participate in this study. Of 48 patients who were examined, 15 did not fulfill the inclusion criteria and eight refused to participate. Written informed consent was obtained from all patients who fulfilled 
the inclusion criteria wherein each agreed to the terms of the research. Before the surgical procedure, all patients completed the OHIP-EDENT, DIDL, and GOHAI questionnaires for the first time.

All surgeries were performed by a single experienced surgeon. Two NDIs (Facility; $2.9 \times 10 \mathrm{~mm}$ ) were installed in the mandible (interforaminal region). Once the abutments were installed and healed, the lower CD was realigned. After 3 months of osseointegration, stud abutments (attachment Equator Facility) were installed prior to loading IMO. Three months after installation of the IMO, the OHRQoL-related questionnaires were completed a second time.

The sample size calculation was based on two previous studies ${ }^{25,28}$ using the following parameters: lower limit of the expected difference between means, standard deviation (SD) of the difference between means, a beta error of $10 \%$, and a one-tailed alpha error of $5 \%$. The minimal significant difference and SD for sample size estimation were calculated based on a final global score of the OHIP-EDENT questionnaire. The obtained CD and IMO values were $40.4 \pm 11.6$ and $54.5 \pm$ 3.9 , respectively. The sample size was increased by $20 \%$ to compensate for potential patient loss and treatment refusal. These calculations indicated that at least 16 participants were needed for this longitudinal study.

\section{OHIP-EDENT questionnaire}

Participants answered a questionnaire related to the use of $\mathrm{CD}$ and IMO that included questions pertaining to physical, functional, social, and psychological consequences. In its original format, each question had three possible answers: "never," "sometimes," or "almost always." Questions 1-20 were reproduced from OHIP-EDENT questionnaire..$^{23,28}$

\section{DIDL questionnaire}

The second questionnaire completed by the patients was the DIDL, which is used to assess the patient perception of oral health and the effects of the medical condition of the mouth and teeth. It is also used to determine the impact of oral intervention on quality of daily life for each domain and classifies patient satisfaction according to a scale. ${ }^{13}$ The DIDL questionnaire consists of 36 questions grouped into five domains: oral comfort, appearance, pain, general performance, and eating and chewing capacity. Questions have three possible answers: "agree," "neutral," or "disagree," graded as 1, 0, or -1 , respectively. ${ }^{29}$ The final scores for each domain represent the average score of the questions related to each domain and are classified as dissatisfied $(<0)$, relatively satisfied $(0-0.69)$, or satisfied $(0.7-1.0) \cdot{ }^{20}$

\section{Auto perception of oral health (GOHAI) questionnaire}

The GOHAI was used to assess the self-reported OHRQoL of the geriatric sample population. ${ }^{19}$ This index consists of 12 multiple choice questions about dental problems that are evaluated in three dimensions: physical (alimentation, speech, and swallowing), psychosocial (care of oral health, dissatisfaction with appearance, oral health self-conscience, and avoidance of social contacts because of dental problems), and pain or discomfort, also considering the use of pain-relieving drugs. There are three possible answers for each question in the GOHAI: "always/often," "sometimes/rarely," and "never," which are scored as 1,2 , and 3, respectively. The total score for each individual varied from 12 to 36 , with a higher score representing better self-perceived oral health.

\section{Statistical analysis}

Data were initially subjected to descriptive analysis and testing of normality. Non-parametric tests were used for analysis of data that was not normally distributed. In order to evaluate the impact of IMO on OHRQoL, the Wilcoxon's matched-pairs signed-rank test was employed, which tests the equality of matched pairs of observations. The level of significance was set at 5\%. In addition, the ES was calculated as the difference in the mean difference between the OHRQoL score before and after the IMO procedure, normalized over the initial SD. The ES was reported in addition to $p$-values, since the latter gives no direct information about the size of the effects. For this reason, reporting of both ES and $p$-values was considered essential. ${ }^{30}$ In general, an ES of 0.2 is considered small, 0.5 is moderate, $>0.8$ is large. ${ }^{31}$ Stata 13.0 software was employed for all analyses (StataCorp LP, College Station, TX, USA). 


\section{Results}

The total sample included 25 patients, 16 of whom were female $(64.0 \%)$, with a mean age of 65.32 years and an average mandibular edentulism duration of 22.7 years. Tables 1, 2, and 3 present the mean, SD, median, and range values for each specific domain before and after $\mathrm{IMO}$, in addition to the ES. Table 1 displays the results from the DIDL questionnaire. There was a significant difference before and after treatment in three domains: appearance $(\mathrm{CD}=0.6 \pm 0.62, \mathrm{IMO}=0.96 \pm 0.2 ; \mathrm{p}=0.011)$, chewing ability $(\mathrm{CD}=0.12 \pm 0.80, \mathrm{IMO}=0.87 \pm 0.42$; $\mathrm{p}=0.003)$, and general performance $(\mathrm{CD}=0.66 \pm 0.44$, $\mathrm{IMO}=0.90 \pm 0.24 ; p=0.003)$. The scores for the pain $(\mathrm{p}=0.44)$ and oral comfort $(\mathrm{p}=0.15)$ domains were not significantly different before and after the IMO procedure. A large ES (0.93) was observed only in the eating and chewing domain. The sample distribution of the domains of the DIDL questionnaire and the associated satisfaction rates are displayed in Figure. The percentage of totally satisfied patients increased in all domains, while the percentage of totally unsatisfied patients decreased.

The analytical results of the GOHAI questionnaire are shown in Table 2. There were significant differences in the scores of two domains: psychosocial $(\mathrm{CD}=11.92 \pm 1.41, \mathrm{IMO}=12.92 \pm 0.49 ; \mathrm{p}=0.005)$ and pain and discomfort $(\mathrm{CD}=13.0 \pm 7.35, \mathrm{IMO}=6.96 \pm 0.45$; $\mathrm{p}=0.0004)$. The scores of the pain and discomfort domain were associated with a large ES (0.83).

Table 3 shows the results of OHIP-EDENT questionnaire. There were significant difference in the scores of functional limitation $(C D=3.28 \pm 1.98$, $\mathrm{IMO}=1.52 \pm 1.55 ; \mathrm{p}=0.0001)$, pain $(\mathrm{CD}=5.12 \pm 3.48$; $\mathrm{IMO}=1.56 \pm 2.85 ; \mathrm{p}=0.0002)$, physical disability $(\mathrm{CD}=1.8 \pm 1.6, \mathrm{IMO}=0.48 \pm 1.04 ; \mathrm{p}=0.0010)$, psychological disability $(\mathrm{CD}=0.68 \pm 0.80, \mathrm{IMO}=0.24 \pm 0.60 ; \mathrm{p}=0.017)$, and handicap $(\mathrm{CD}=0.56 \pm 0.87, \mathrm{IMO}=0.2 \pm 0.64$;

Table 1. Mean and SD values of the DIDL domains pre- and post-IMO treatment evaluation, and ES analysis.

\begin{tabular}{|c|c|c|c|c|c|c|c|c|c|c|c|c|}
\hline \multirow[b]{2}{*}{ DIDL } & \multicolumn{5}{|c|}{ Before IMO } & \multicolumn{5}{|c|}{ After IMO } & \multirow[b]{2}{*}{ p-value } & \multirow{2}{*}{$\begin{array}{c}\text { ES } \\
\text { Mean }\end{array}$} \\
\hline & Mean & SD & Median & Range & $\begin{array}{c}\text { Interquartile } \\
\text { interval }\end{array}$ & Mean & SD & Median & Range & $\begin{array}{l}\text { Interquartile } \\
\text { interval }\end{array}$ & & \\
\hline Appearance & 0.6 & 0.62 & 1 & $-1-1$ & $0-1$ & 0.96 & 0.2 & 1 & $0-1$ & $1-1$ & 0.011 & 0.57 \\
\hline Pain & -0.04 & 0.74 & -0.25 & $-1-1$ & $-0.5-0.5$ & 0.24 & 0.93 & 1 & $-1-1$ & $-1-1$ & 0.44 & 0.38 \\
\hline Oral comfort & 0.017 & 0.41 & 0.14 & $-1-0.71$ & $-0.14-0.28$ & 0.24 & 0.78 & 0.71 & $-1-1$ & $-0.57-0.71$ & 0.15 & 0.54 \\
\hline $\begin{array}{l}\text { Eating and } \\
\text { Chewing }\end{array}$ & 0.12 & 0.80 & 0 & $-1-1$ & $-0.66-1$ & 0.87 & 0.42 & 1 & $-1-1$ & $1-1$ & 0.003 & 0.93 \\
\hline $\begin{array}{l}\text { General } \\
\text { performance }\end{array}$ & 0.66 & 0.44 & 0.86 & $-0.73-1$ & $0.46-1$ & 0.90 & 0.24 & 1 & $0.13-1$ & $1-1$ & 0.003 & 0.56 \\
\hline
\end{tabular}

*p-value from Wilcoxon's matched-pairs signed-ranks test; IMO: implant-retained mandibular overdentures.

Table 2. Mean and SD values of the GOHAI domains pre- and post-IMO treatment evaluation, and ES analysis.

\begin{tabular}{|c|c|c|c|c|c|c|c|c|c|c|c|c|}
\hline \multirow[b]{2}{*}{ GOHAl } & \multicolumn{5}{|c|}{ Before IMO } & \multicolumn{5}{|c|}{ After IMO } & \multirow{2}{*}{$p$-value } & \multirow{2}{*}{$\begin{array}{c}\text { ES } \\
\text { Mean }\end{array}$} \\
\hline & Mean & SD & Median & Range & $\begin{array}{c}\text { Interquartile } \\
\text { interval }\end{array}$ & Mean & SD & Median & Range & $\begin{array}{c}\text { Interquartile } \\
\text { interval }\end{array}$ & & \\
\hline Physical & 9.12 & 1.01 & 9 & $7-10$ & $8-10$ & 9.4 & 0.91 & 10 & $7-10$ & $9-10$ & 0.33 & 0.27 \\
\hline Psychosocial & 11.92 & 1.41 & 13 & $9-13$ & $11-13$ & 12.92 & 0.49 & 13 & $11-13$ & $13-13$ & 0.005 & 0.71 \\
\hline $\begin{array}{l}\text { Pain and } \\
\text { discomfort }\end{array}$ & 7.6 & 0.96 & 8 & $6-9$ & $7-8$ & 6.96 & 0.45 & 7 & $5-8$ & $7-7$ & 0.0004 & 0.83 \\
\hline Global score & 28.3 & 2.1 & 29 & $22-31$ & $27-30$ & 29.3 & 1.42 & 30 & $24-31$ & $29-30$ & 0.077 & 0.45 \\
\hline
\end{tabular}

*p-value from Wilcoxon's matched-pairs signed-ranks test; IMO: implant-retained mandibular overdentures. 
Table 3. Mean and SD values of the OHIP-EDENT domains pre- and post-IMO treatment evaluation, and ES analysis.

\begin{tabular}{|c|c|c|c|c|c|c|c|c|c|c|c|c|}
\hline \multirow[b]{2}{*}{ OHIP-EDENT } & \multicolumn{5}{|c|}{ Before IMO } & \multicolumn{5}{|c|}{ After IMO } & \multirow[b]{2}{*}{ p-value } & \multirow{2}{*}{$\begin{array}{c}\text { ES } \\
\text { Mean }\end{array}$} \\
\hline & Mean & SD & Median & Range & $\begin{array}{c}\text { Interquartile } \\
\text { interval }\end{array}$ & Mean & SD & Median & Range & $\begin{array}{c}\text { Interquartile } \\
\text { interval }\end{array}$ & & \\
\hline Functional limitation & 3.28 & 1.98 & 3 & $0-6$ & $2-5$ & 1.52 & 1.55 & 1 & $0-6$ & $0-2$ & 0.0001 & 0.89 \\
\hline Physical pain & 5.12 & 3.48 & 5 & 0-14 & $2-7$ & 1.56 & 2.86 & 0 & $0-12$ & $0-2$ & 0.0002 & 1.02 \\
\hline $\begin{array}{l}\text { Psychological } \\
\text { discomfort }\end{array}$ & 0.72 & 1.2 & 0 & $0-4$ & $0-1$ & 0.16 & 0.47 & 0 & $0-2$ & $0-0$ & 0.065 & 0.46 \\
\hline Physical disability & 1.8 & 1.6 & 2 & $0-5$ & $0-3$ & 0.48 & 1.04 & 0 & $0-4$ & $0-0$ & 0.0010 & 0.84 \\
\hline $\begin{array}{l}\text { Psychological } \\
\text { disability }\end{array}$ & 0.68 & 0.80 & 0 & $0-2$ & $0-1$ & 0.24 & 0.60 & 0 & $0-2$ & $0-0$ & 0.017 & 0.55 \\
\hline Social disability & 0.48 & 0.87 & 0 & $0-3$ & $0-1$ & 0.12 & 0.33 & 0 & $0-1$ & $0-0$ & 0.15 & 0.41 \\
\hline Handicap & 0.56 & 0.87 & 0 & $0-3$ & $0-1$ & 0.2 & 0.64 & 0 & $0-3$ & $0-0$ & 0.032 & 0.41 \\
\hline Global score & 11.2 & 7.5 & 9 & $0-26$ & $5-18$ & 3.8 & 5.42 & 2 & 0-19 & $1-3$ & 0.0001 & 0.97 \\
\hline
\end{tabular}

*p-value from Wilcoxon's matched-pairs signed-ranks test; IMO: implant-retained mandibular overdentures.

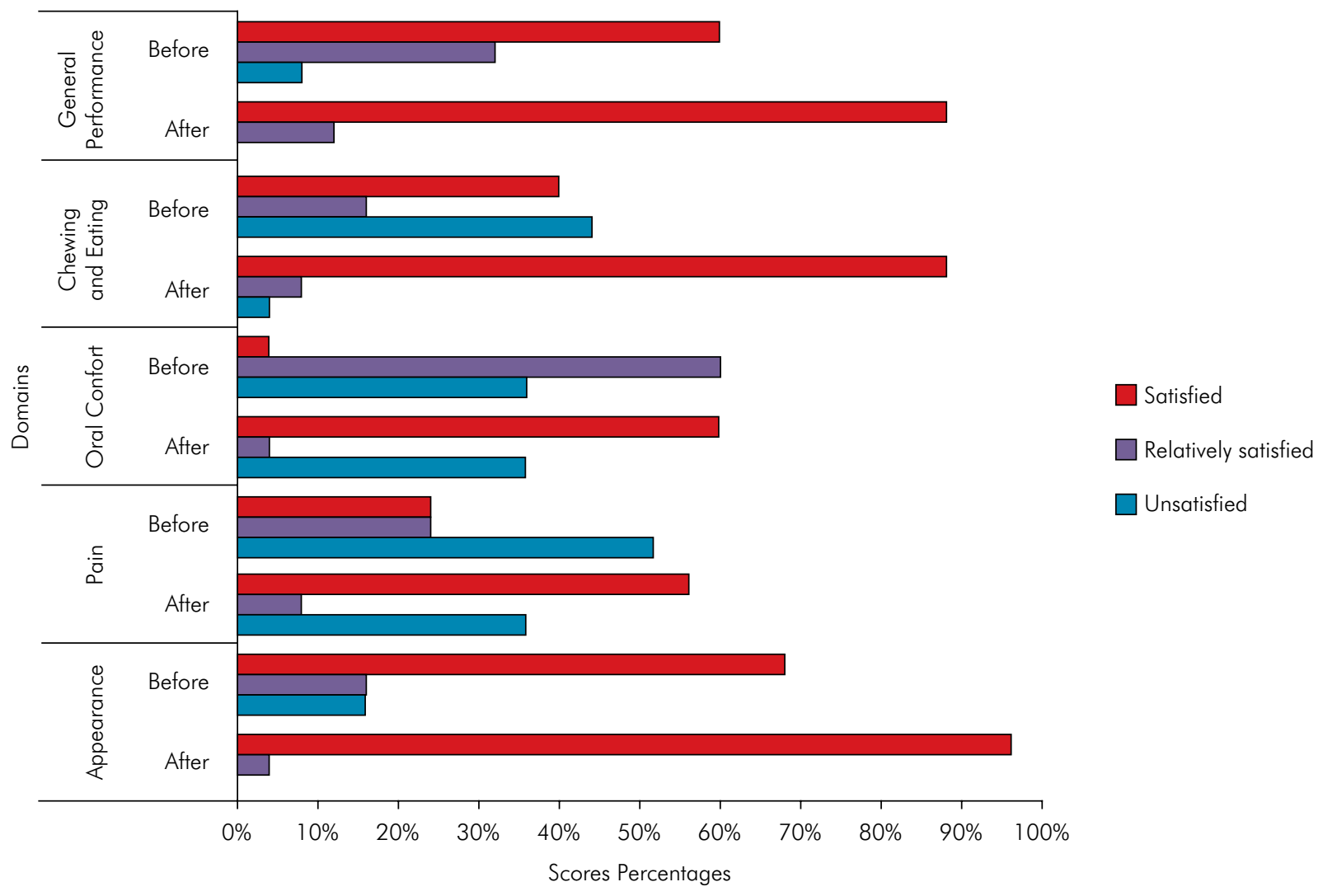

Figure. Sample distribution in three satisfaction categories for each domain of the DIDL questionnaire.

$p=0.032)$. Furthermore, there was a significant difference between the baseline and final global scores of this questionnaire $(p=0.001)$. No differences were noted in the psychological discomfort and social disability domains $(\mathrm{p}>0.05)$. The $\mathrm{ES}$ results indicate large differences in the following domains: functional limitation (0.89), physical pain (1.02), physical disability (0.84), and global score (0.97). 


\section{Discussion}

Locker et al. ${ }^{11}$ defined OHRQoL measurement instruments as those that assess the proportion of oral diseases and disorders, which in turn affect the function and assessment of psychosocial well-being. The differences between the questionnaires designed for this purpose relate to the number of questions, the question content, the answer format, the grouping of topics in different domains, and the number of domains. ${ }^{32}$ Most studies that investigate the subjective perception of edentulous patients before and after IMO rehabilitation evaluate OHRQoL based on one questionnaire (e.g., DIDL, GOHAI, or OHIP-EDENT). Consequently, the limitations and differences in sensitivity across various domains of each questionnaire with respect to the others remain unknown. Furthermore, it is unclear which domains have the largest impact on OHRQoL after IMO treatment. Thus, the present study compared the results from three questionnaires (DIDL, GOHAI, and OHIP-EDENT) to assess the impact of IMO treatment on OHRQoL of denture wearers before IMO and after 3 months of adaptation and rehabilitation. The results showed that the self-reported OHRQoL effectively increased after rehabilitation and treatment with IMO. There were significant differences in several domains of the three questionnaires before and after IMO installation. Along with the major change in OHRQoL perception, the largest clinical effect perceived by patients occurred in areas related to the functional benefits established by IMO. The DIDL questionnaire indicated a significant improvement in the chewing and eating domain. The GOHAI questionnaire indicated a significant shift in the pain and discomfort domain, which included questions related to general mouth comfort along with pain and discomfort while chewing. The OHIP-EDENT results indicated significant improvements in the functional limitation, physical pain, and physical disability domains, which contain questions regarding comfort, ability, and retention of the prosthesis during chewing, as well as general pain and discomfort.

In a study of rehabilitated edentulous patients with total or partial dentures, Al-Omiri et al. ${ }^{13}$ noted an increase in overall DIDL satisfaction and contentment with appearance, pain, oral comfort, general performance, and chewing after treatment. However, Hantash et al. ${ }^{33}$ found that more than $50 \%$ of patients with conventional CD was not completely satisfied with the prosthesis. In this study, elderly patients were more satisfied with appearance and less satisfied with oral comfort and general performance. Hantash et al. ${ }^{33}$ also observed a significant increase in mean DIDL scores for appearance, chewing, and general performance after IMO installation. This is entirely consistent with the results of the present study and may be explained by the increased retention and stability provided by IMO. The latter can improve satisfaction with chewing and increase the capacity of patients to perform daily activities and social interactions. ${ }^{22,34}$

The ES results after IMO treatment revealed a large improvement in patient perception of eating and chewing (ES = 0.93), and a moderate improvement in appearance, oral comfort, and general performance ( $E S=0.57,0.54$, and 0.56 , respectively). Therefore, the DIDL scores showed that the main improvement due to IMO treatment was related to the ability to bite and chew food. Patient classification according to the satisfaction scale of the DIDL demonstrated the efficacy of IMO to improve quality of life. Furthermore, the percentage of totally satisfied patients increased in all domains, while the percentage totally unsatisfied patients decreased. In agreement with these findings, Packer et al..$^{24}$ used a modified version of the DIDL questionnaire for a sample of patients with Parkinson's disease and observed a significant improvement in OHRQoL after rehabilitation with overdentures and fixed prostheses, with improved satisfaction, nutrition, and oral health.

Edentulous patients wearing $\mathrm{CD}$ with a low $\mathrm{GOHAI}$ index prior to IMO treatment and fixed prostheses, recorded significant increases in mean scores that reflect improvement in OHRQoL in all three areas of the GOHAI (functional, psychosocial, pain and discomfort), while there was no difference between subjects that received fixed prostheses or overdentures. ${ }^{25}$ The results of the present study showed that after IMO treatment, patients reported significant improvements $(p<0.05)$ in the psychosocial and pain and discomfort domains. The increase in the psychosocial domain highlights the fact that the OHRQoL of patients improved 
after IMO treatment, as demonstrated in previous studies. ${ }^{25}$ Although the global score increased after IMO installation, there was no significant difference between the initial and final scores.

According to Locker et al. ${ }^{35}$, the GOHAI questionnaire gives greater emphasis to functional limitations, as demonstrated by the physical and pain and discomfort domains. This is in accordance with the present results, where the pain and discomfort domain exhibited the largest ES. This demonstrates that the main clinical improvement in OHRQoL observed via the GOHAI resulted from an increase in oral comfort during meals, less analgesic use, and less sensitive gums. In addition, the results of the present study showed a moderate ES in the psychosocial domain after IMO treatment. The latter reflects a moderate improvement in maintaining social relationships, satisfaction with smile appearance, and decreased concern about the conditions of the gums and prostheses.

The OHIP-EDENT is one of the most widely used OHRQoL assessment tools in the literature for analysis of the perception of CD and IMO treatment.916,26,27,28 This questionnaire focuses on the "social impact" of oral disorders, such as dysfunction, discomfort, and disability. ${ }^{36}$ Higher OHIP-EDENT scores in each domain indicate poor quality of life. Souza et al. ${ }^{37}$ used the OHIP-Edent questionnaire to compare IMO for mini-implants and IMO for conventional diameter implants, and found that the first treatment resulted in slightly better OHRQoL. An experimental study that used evaluation with the OHIP-EDENT 2 months after IMO installation found that all seven domains and overall scores significantly improved, in accordance with previous results. ${ }^{9,27}$ Awad et al..$^{26}$ showed that IMO treatment can improve OHRQoL as soon as 2 months after rehabilitation. Alfadda et al. ${ }^{9}$ demonstrated OHRQoL improvement, as indicated by the OHIP-20 after rehabilitation with IMO, which remained stable in the initial 5-year period, showing that this treatment remains satisfactory for long follow-up periods.

The results of this study indicate a significant increase in OHRQoL $(p<0.05)$ after rehabilitation with IMO in the functional limitation, physical pain, physical disability, psychological disability, handicap, and global score domains. All aforementioned domains were associated with large ES, except the psychological disability and handicap domains, indicating that the magnitude of OHRQoL increase after IMO treatment is considerable, in accordance with a previous report. ${ }^{27}$ These results are in line with a wide range of evidence demonstrating that IMO rehabilitation was viable and satisfactory for elderly patients with edentulous mandibles. The most noticeable improvements at 3 months post treatment (ES > 0.8) were observed in functional domains: i.e., eating and chewing (DIDL); pain and discomfort (GOHAI); and functional limitation, physical pain, and physical disability (OHIP-EDENT). In addition, this study provides unique results about OHRQoL evaluation from the perspective of three different questionnaires (DIDL, GOHAI, and OHIP-EDENT).

Finally, these results demonstrate the usefulness of ES calculations for the evaluation of clinical perception of oral treatment. Further studies with longer follow-up periods are needed to elucidate the long-term effects of IMO rehabilitation. The differences between the three questionnaires indicate different sensitivities of each questionnaire for various aspects of OHRQoL and that a combined approach is beneficial for extracting the maximal amount of OHRQoL-related information.

\section{Conclusion}

The DIDL, OHII-EDENT, and GOHAI questionnaires were used to assess changes in quality of life after rehabilitation with IMO among elderly patients with difficulty adapting to conventional dentures. Elderly conventional $\mathrm{CD}$ wearers reported major improvements in OHRQOL 3 months after installment of IMO, with main improvements observed in the functional aspects of the prostheses and pain perception. ES calculations show that the most important improvements occurred in the chewing and eating domain of the DIDL questionnaire, in the pain and discomfort domain of the GOHAI questionnaire, and the physical pain domain of the OHIP-EDENT questionnaire.

\section{Acknowledgements}

The authors acknowledge financial support from the CNPq (National Council for Scientific and Technological Development; grant no. 476170/2013-3) and the Neodent's Research Support Program. 


\section{References}

1. Vos T, Flaxman AD, Naghavi M, Lozano R, Michaud C, Ezzati M et al. Years lived with disability (YLDs) for 1160 sequelae of 289 diseases and injuries 1990-2010: a systematic analysis for the Global Burden of Disease Study 2010. Lancet. 2012;380(9859):2163-96. doi:10.1016/S0140-6736(12)61729-210.1016/S0140-6736(12)61729-2

2. Kassebaum NJ, Bernabé E, Dahiya M, Bhandari B, Murray CJL, Marcenes W. Global burden of severe periodontitis in 1990-2010: a systematic review and meta-regression. J Dent Res. 2014;93(11):1045-53. doi:10.1177/0022034514552491

3. Carlsson GE, Omar R. The future of complete dentures in oral rehabilitation. A critical review. J Oral Rehabil. 2010;37(2):143-56. doi:10.1111/j.1365-2842.2009.02039.x

4. Felton DA. Edentulism and comorbid factors. J Prosthodont. 2009;18(2):88-96. doi:10.1111/j.1532-849X.2009.00437.x

5. Huumonen S, Haikola B, Oikarinen K, Söderholm AL, Remes-Lyly T, Sipilä K. Residual ridge resorption, lower denture stability and subjective complaints among edentulous individuals. J Oral Rehabil. 2012;39(5):384-90. doi: $0.1111 / j .1365-2842.2011 .02284 . x$

6. Carlsson GE. Clinical morbidity and sequelae of treatment with complete dentures. J Prosthet Dent. 1998;79(1):17-23. doi:10.1016/S0022-3913(98)70188-X

7. Allen PF, McMillan AS. A review of the functional and psychosocial outcomes of edentulousness treated with complete replacement dentures. J Can Dent Assoc. 2003;69(10):662.

8. Emami E, de Souza RF, Kabawat M, Feine JS. The impact of edentulism on oral and general health. Int J Dent. 2013;2013:498305. doi:10.1155/2013/498305

9. Alfadda SA, Attard NJ, David LA. Five-year clinical results of immediately loaded dental implants using mandibular overdentures. Int J Prosthodont. 2009;22(4):368-73.

10. Papadaki E, Anastassiadou V. Elderly complete denture wearers: a social approach to tooth loss. Gerodontology. 2012;29(2):e721-7. doi:10.1111/j.1741-2358.2011.00550.x

11. Locker D, Clarke M, Payne B. Self-perceived oral health status, psychological well-being, and life satisfaction in an older adult population. J Dent Res. 2000;79(4):970-5. doi:10.1177/00220345000790041301

12. Fernandez-Estevan L, Selva-Otaolaurruchi EJ, Montero J, Sola-Ruiz F. Oral health-related quality of life of implant-supported overdentures versus conventional complete prostheses: retrospective study of a cohort of edentulous patients. Med Oral Patol Oral Cir Bucal. 2015;20(4):e450-8. doi:10.4317/medoral.20498

13. Al-Omiri MK, Sghaireen MG, Al-Qudah AA, Hammad OA, Lynch CD, Lynch E. Relationship between impacts of removable prosthodontic rehabilitation on daily living, satisfaction and personality profiles. J Dent. 2014;42(3):366-72. doi:10.1016/j.jdent.2013.12.010
14. Furuyama $C$, Takaba $M$, Inukai M, Mulligan R, Igarashi Y, Baba K. Oral health-related quality of life in patients treated by implant-supported fixed dentures and removable partial dentures. Clin Oral Implants Res. 2012;23(8):958-62. doi:10.1111/j.1600-0501.2011.02247.x

15. Raghoebar GM, Meijer HJ, Stellingsma K, Vissink A. Addressing the atrophied mandible: a proposal for a treatment approach involving endosseous implants. Int J Oral Maxillofac Implants. 2011;26(3):607-17. doi:

16. Jofre J, Castiglioni $X$, Lobos CA. Influence of minimally invasive implant-retained overdenture on patients' quality of life: a randomized clinical trial. Clin Oral Implants Res. 2013;24(10):1173-7. doi:10.1111/j.1600-0501.2012.02529.x

17. Stellingsma K, Raghoebar GM, Meijer HJ, Stegenga B. The extremely resorbed mandible: a comparative prospective study of 2-year results with 3 treatment strategies. Int J Oral Maxillofac Implants. 2004;19(4):563-77. doi:

18. Sierra-Sánchez JL, Martínez-González A, García-Sala Bonmatí F, Mañes-Ferrer JF, Brotons-Oliver A. Narrow-diameter implants: are they a predictable treatment option? A literature review. Med Oral Patol Oral Cir Bucal. 2014;19(1):e74-81. doi:10.4317/medoral.19306

19. Atchison KA, Dolan TA. Development of the Geriatric Oral Health Assessment Index. J Dent Educ. 1990;54(11):680-7.

20. Leao A, Sheiham A. Relation between clinical dental status and subjective impacts on daily living. J Dent Res. 1995;74(7):1408-13. doi:10.1177/00220345950740071301

21. Slade GD, Spencer AJ. Development and evaluation of the Oral Health Impact Profile. Community Dent Health. 1994;11(1):3-11.

22. Slade GD. Derivation and validation of a short-form oral health impact profile. Community Dent Oral Epidemiol. 1997;25(4):284-90. doi:10.1111/j.1600-0528.1997.tb00941.x

23. De Souza RF, Leles CR, Guyatt GH, Pontes CB, Della Vecchia MP, Neves FD. Exploratory factor analysis of the Brazilian OHIP for edentulous subjects. J Oral Rehabil. 2010;37(3):202-8. doi:10.1111/j.1365-2842.2009.02043.x

24. Packer M, Nikitin V, Coward T, Davis DM, Fiske J. The potential benefits of dental implants on the oral health quality of life of people with Parkinson's disease. Gerodontology. 2009;26(1):11-8. doi:10.1111/j.1741-2358.2008.00233.x

25. Fillion $M$, Aubazac D, Bessadet $M$, Allègre $M$, Nicolas E. The impact of implant treatment on oral health related quality of life in a private dental practice: a prospective cohort study. Health Qual Life Outcomes. 2013;11(1):197. doi: 10.1186/1477-7525-11-197

26. Awad MA, Lund JP, Shapiro SH, Locker D, Klemetti E, Chehade A et al. Oral health status and treatment satisfaction with mandibular implant overdentures and conventional dentures: a randomized clinical trial in a senior population. Int J Prosthodont. 2003;16(4):390-6. 
27. Heydecke G, Locker D, Awad MA, Lund JP, Feine JS. Oral and general health-related quality of life with conventional and implant dentures. Community Dent Oral Epidemiol. 2003;31(3):161-8. doi:10.1034/j.1600-0528.2003.00029.x

28. Allen F, Locker D. A modified short version of the oral health impact profile for assessing health-related quality of life in edentulous adults. Int J Prosthodont. 2002;15(5):446-50.

29. Al-Omiri MK, Hammad OA, Lynch E, Lamey PJ, Clifford TJ. Impacts of implant treatment on daily living. Int J Oral Maxillofac Implants.2011;26(4): 877-886.

30. Sullivan GM, Feinn R. Using effect size-or why the $p$ value is not enough. J Grad Med Educ. 2012;4(3):279-82. doi:10.4300/JGME-D-12-00156.1

31. Kazis LE, Anderson JJ, Meenan RF. Effect sizes for interpreting changes in health status. Med Care. 1989;27(3 Suppl):S178-89. doi:10.1097/00005650198903001-00015

32. John MT, Hujoel P, Miglioretti DL, LeResche L, Koepsell TD, Micheelis W. Dimensions of oral-health-related quality of life. J Dent Res. 2004;83(12):956-60. doi:10.1177/154405910408301213
33. Hantash RO, AL-Omiri MK, Yunis MA, Dar-Odeh N, Lynch E. Relationship between impacts of complete denture treatment on daily living, satisfaction and personality profiles. J Contemp Dent Pract. 2011;12:200-7. doi:10.5005/jp-journals-10024-1035

34. Toman M, Toksavul S, Saracoglu A, Cura C, Hatipoglu A. Masticatory performance and mandibular movement patterns of patients with natural dentitions, complete dentures, and implant-supported overdentures. Int J Prosthodont. 2012;25(2):135-7.

35. Locker D, Matear D, Stephens M, Lawrence H, Payne B. Comparison of the GOHAI and OHIP-14 as measures of the oral health-related quality of life of the elderly. Community Dent Oral Epidemiol. 2001;29(5):373-81. doi:10.1034/j.1600-0528.2001.290507.x

36. Locker D, Allen F. What do measures of "oral health-related quality of life" measure? Community Dent Oral Epidemiol. 2007;35(6):401-11. doi:10.1111/j.1600-0528.2007.00418.x

37. Souza RF, Ribeiro AB, Della Vecchia MP, Costa L, Cunha TR, Reis AC et al. Mini vs. Standard Implants for Mandibular Overdentures: A Randomized Trial. J Dent Res. 2015;94(10):1376-84. doi:10.1177/0022034515601959 